INTERNATIONAL DESIGN CONFERENCE - DESIGN 2018

https://doi.org/10.21278/idc.2018.0431

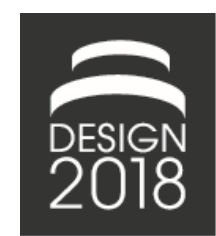

\title{
TOWARDS A DESIGN-METHOD SELECTION FRAMEWORK FOR MULTIDISCIPLINARY PRODUCT DEVELOPMENT
}

\author{
B. Guérineau, L. Rivest, M. Bricogne, A. Durupt and B. Eynard
}

\begin{abstract}
Within product development, software and connectivity are playing an ever-increasing role, driven by information and communication technologies, part of the Industrie 4.0 paradigm. Product development has evolved accordingly to integrate new disciplines. Multidisciplinary product development (MPD) is supported by a variety of approaches, processes, methods and tools that should be carefully chosen and combined. This paper investigates MPD-oriented criteria that will lead to selecting appropriate concepts and techniques, proposing criteria that illustrate the features and considerations of MPD.
\end{abstract}

Keywords: design methods, product development, complex systems, industry 4.0, digital transformation

\section{Introduction}

Most industrial sectors, including aeronautics, automotive and consumer goods, are developing products that most integrate various disciplines. This kind of development, called multidisciplinary product development (MPD) is defined in this paper as a product development that involves different engineering disciplines such as mechanics, electronics, electricity, information and communication technology (ICT) for connectivity implementation. Examples of such products are mechatronic systems (Abramovici and Bellalouna, 2007), micro-electro-mechanical systems (Gad-el-Hak, 2002), and cyberphysical-systems (Baheti and Gill, 2011; Rajkumar, 2012). Moreover, the recent Internet of Things IoT (Giusto et al., 2010) trend is driving product evolution towards connectivity integration to reach the so-called smart products (Cronin, 2010). All of these examples are the result of products' evolution process.

Since the first industrial revolution, products can be enriched by new disciplines. (Isermann, 2002) describes this continuous products' evolution process. According to Isermann, products were pure mechanical systems before 1900, and then they integrate successively electricity, automatic control and electronic components, first analog and then digital, to finally reach the so-called mechatronic systems. Mechatronic products, integrating mainly mechanical, electronic and electro-mechanical components, are now evolving to integrate an increasing proportion of software. This observation is underscored by (Fricker, 2012), "products like phones, cars, and airplanes are increasingly softwarebased, rather than being electro-mechanical devices". Ebert establishes a similar statement: "Software-intensive systems as used in automobiles, aircraft, medical, transportation, utilities, and industrial automation deliver today 50-70 percent of the value of these solutions, and this will further grow" (Ebert, 2013). Within this products' evolution, there has clearly been increasing interest in software, and now for connectivity. Both are driven by ICT and they are leading to the development of the digital and ubiquitous connectivity era. Advances in digital technologies and connectivity are 
growing in tandem and infusing in many industrial domains. This product and industry revolution within the digital and connectivity era has led to the dawn of a fourth industrial revolution termed Industrie 4.0.

Industrie 4.0, a German concept, emerged in the 2010's (Kagermann et al., 2013; Anderl, 2014; Hermann et al., 2016) and aggregates a set of ten key technological groups (Danjou et al., 2017). Industrie 4.0 can be seen as the realisation of the fourth industrial revolution based on those technological groups. From our perspective, Industrie 4.0 is an industrial and technological paradigm positioning digital technologies, software and connectivity at the core of companies in order to take better advantage of manufacturing capacities and capabilities, manufactured products, their associated services and development. This paradigm is already leading to the transformation of products, manufacturing capacities and capabilities, development processes, and company business models and organization, and thus on how companies are designing their products. This article focuses on product development within the Industrie 4.0 paradigm.

Pushed by this new paradigm, products are already evolving and thus how they are developed must evolve accordingly by seeking for a better integration of multiple disciplines. MPD, as envisioned in this paper, aims at merging software, hardware and connectivity to reach the current stage of product evolution. Each discipline has its specific background and dedicated approaches, processes, methods and tools have been created to support them independently. As an example, agile methods were initially software-oriented whereas project-planned methods were used in hardware design (Guérineau et al., 2016). Software and hardware use different processes (Crnkovic et al., 2003; Kääriäinen and Välimäki, 2009) and thus different methods and tools needed to be designed. Designing products that include both software and hardware is very challenging. Moreover, (Guérineau et al., 2016) emphasize that "very few of the existing methods were initially developed to cope with multidisciplinary approaches". It is supposed that some of the discipline-dedicated approaches, processes, methods and tools may be transposed to MPD under certain conditions. The criteria required to establish and validate this transposition must still be developed and validated.

As underlined in this introduction, few methods and tools were initially designed to tackle the particular features of MPD. This paper aims to highlight MPD's features in order to determine the criteria with which to evaluate the approaches, processes, methods and tools that are indeed able to support MPD. The following section introduces a classification based on four levels to be used as a filter for a state-of-the-art analysis and to categorize criteria. The third section investigates how products and methods are linked, and then how design method selection is processed via that link to finally explore MPD features and expectations. The fourth section establishes some criteria that illustrate MPD features and expectations. Each criterion is matched to one of the corresponding four levels defined in the second section. Finally, a conclusion and outlook on further work are proposed in the last section.

\section{Different levels for product development}

As explained in the first section, products' evolutions are now driven by Industrie 4.0 in this era of digital technologies information and ubiquitous connectivity. Product development must integrate new constraints and incorporate the growing number of disciplines involved. A large choice of design concepts and techniques is now available, although not all methods have the same granularity or the same impact. Some methods are more general and closer to a philosophy, whereas others are much more operational and intervene at a particular moment of the development process for a specific purpose. Based on this observation, we propose a four-level classification inspired by (Estefan, 2008). The highest level is the approach; the lowest is the tool. Between these two are the process and the method levels. Each of these levels are explained below; their positioning is related to Girard and Doumeingts' work which describes three levels: strategic, operational and tactical (Girard and Doumeingts, 2004). The Agile approach and its realization into processes, methods and tools is an exemplification of the following four levels, defined as:

- The approach can be envisioned as an overall philosophy. It is a set of principles that allow product development to be addressed at a macroscopic scale. For approach operationalization, principles can be transposed in the form of processes, methods and tools. Approach is related to 
the strategic level. Agile is an example of an approach as it encompasses twelve principles listed within the Agile Manifesto (Beck et al., 2001).

- The process gathers a series of temporally organized mesoscopic steps - ordered sequentially or concurrently - to fulfil a purpose; these steps include the input elements (customer's requirements, specifications, etc.) and resources (financial, human, IT, etc.) required to obtain a result that could take the form of a product. A process can be iterative and integrate established milestones. It organizes the product development steps and relies on methods and tools for steps operationalization. A process operates at a tactical level. One process that can emerge from Agile is Scrum (Schwaber, 1997), as it is a series of steps.

- The method is a set of rules and engineering practices are implemented within a process, thereby allowing a technical procedure to be realized and so reach a result. A method's tasks can be realized using tools. Any method is part of a more general process. A method is positioned at Girard and Doumeimgts' operational level. In accordance to the Scrum process, a method such as Continuous Integration (Booch et al., 2007), considered as an engineering practice, can finds its place in an Agile context (Stolberg, 2009).

- The $\boldsymbol{t o o l}$ is where a delineated method's task to obtain and/or improve a result is realized by acting on a particular element. A tool is thus able to support or help in the realization of a task. The tool is related to the operational level (Girard and Doumeingts, 2004). A tool intercedes for a defined purpose and at a specific moment of a product's development. The term tool includes editing tools to create/produce/improve a result and management tools designed to maintain a result/a state. Tools can be fully or partially automated. On an Agile instantiation product, backlogs can be considered as tools (Cooper and Sommer, 2016).

Figure 1(A) summarises the four levels and their hierarchical relations. The approach is on top, the process is the second level, method is third and tools are the base. Reading the pyramid from the top to the bottom, levels are ordered by their increasing operational level. Reading the pyramid from the bottom to the top, the levels are ordered by their level of abstraction.

In terms of temporality, as illustrated in Figure 1(A) and (B), the approach remains generally the same throughout the whole product's development. Several processes can be nested at the same level or in a hierarchical manner. For example, a series of processes for conducting product development may be included with the development design-dedicated process, and then become industrialization-oriented. Process supports a major part of a project's duration. A method's implication is shorter as it deals with one or several process's steps. Finally, the tool is short-acting as it aims at assisting the method or process to achieve a specific purpose.

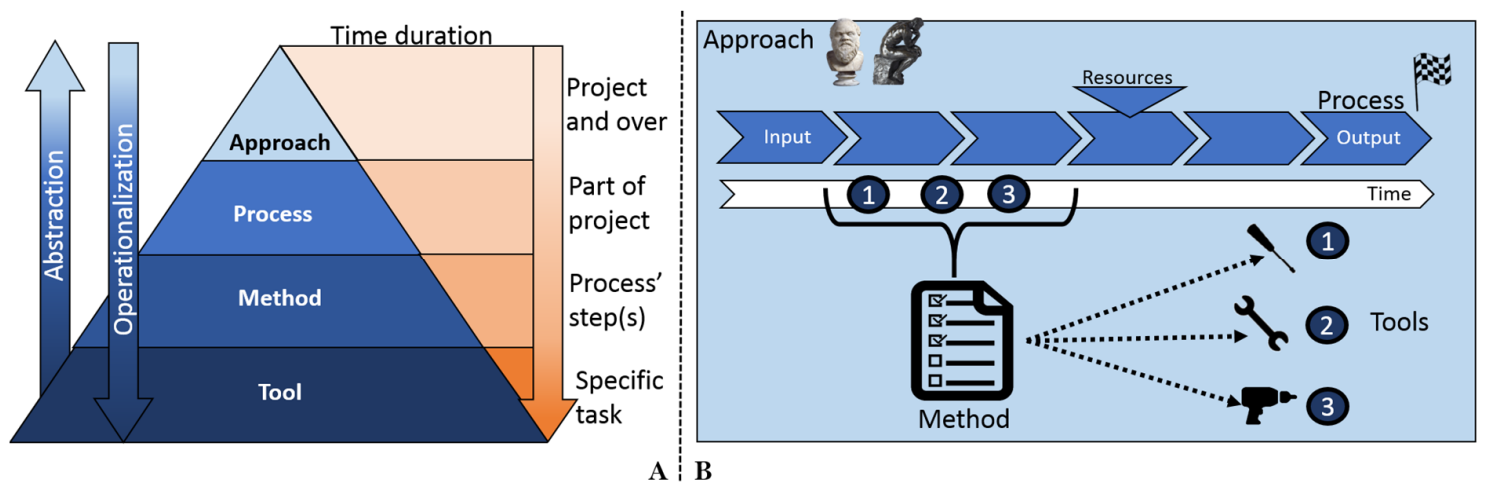

Figure 1. Structure of the four-level classification for product development

This four-layer classification has relative interactions over the hierarchical order. Process is a project's guideline and is able to call a method to realize a step or a sub-set of a step, while a process is a set a mesoscopic steps. A method is a set of rules and engineering practices whose first vocation is to be applicable to leading product development through a development process step. Finally, the tool, called 
by a method or directly by a process, acts on product development for a defined purpose and at a specific moment. Process, method and tool have inherent bonds with an approach.

To address the four different levels: approach, process, method and tool, we propose the acronym PDSCT (Product Development Supporting Concepts and Techniques). In the next sections, the four levels of PDSCT will be used to provide a filter for a state-of-the-art analysis and then to categorize the identified criteria.

\section{Multidisciplinary product development: The state-of-the-art}

The previous section describes a four-level classification to specify which level of product development is addressed and offer a reading grid. This section is divided into three sub-sections. The first one demonstrates the link between a product and a method in an MPD context, and that this link, if it exists, is rarely underscored or justified. The second sub-section focuses on a PDSCT selection process that can be documented by a direct opposition. Finally, the third sub-section introduces and describes MPD issues and features.

\subsection{The importance of a product's specificity link in MPD}

It is obvious that hardware and software products rely on different PDSCTs. A hardware product has some features that a software product does not, and vice versa. Those features allow companies to choose between software-oriented methods or hardware-dedicated methods. Thus, there is a link between the product to develop and the method used for its design. This relationship is defined in this paper as a product to concepts and techniques specificity link (PCTSL). This PCTSL is commonly acknowledged in a discipline-specific development. Nonetheless, in a MPD context, hardware, software and now connectivity features are merged and mixed together, leading to complex product features and difficult PDSCT selection. The PCTSL still exists but it is rarely formalized.

Examples of PCTSL in an MPD context can be found throughout CPS and mechatronic systems design. At the approach level, (Bricogne et al., 2016) propose to make use of Agile for mechatronic design as mechatronic has a growing software part. They also envisioned the development of mechatronic products with model-based system engineering (MBSE).

On a process level, system engineering has also branched to become mechatronic-dedicated through the work of Kleiner and Kramer (2013) and the VDI 2206 (VDI, 2004) via an adapted V-cycle process. Hehenberger also proposed using hierarchical design models in his solution for mechatronic design (Hehenberger et al., 2010). His work reuses the concepts of design parameters and functional requirements that are also present in axiomatic design (Suh, 1998).

On a method level, for simulation and architecture, (Hu et al., 2016) propose to make use of multi-agent or agent-based methodologies which originate from software. When methods are proposed for MPD, the bond between the proposed method and a product's features is rarely emphasized.

At the tool level, for system modelling, (Turki et al., 2005) recommend using the SysML/UML language

To summarize, CPS design is relatively similar to mechatronic design as they share common PDSCT. The PCTSL is effective on different levels and while present, is rarely treated as important. To highlight this link, characterizations of both methods and products are required, as well as a solid comprehension of how this link is established. This work next leads to an investigation of which criteria a PCTSL is based on. The next sub-section explores PDSCT selection to highlight existing selection methods and their respective criteria.

\subsection{Selecting supporting concepts and techniques: MPD is rarely addressed}

The previous sub-section presents the existence of PCTSLs in MPD as shown in a literature review. A PCTSL establishes a bond between a product and PDSCTs. This section focuses on current PDSCT selection criteria that can be formalized in a PCTSL.

This concept of selecting PDSCT based on criteria is explored by (Nomaguchi et al., 2012) and applied to product platform and family design scope. Nomaguchi et al.'s proposed work is in the form of a matrix 
called "Design Method Selection Matrix" and relies on a method criteria-based rating and mathematical operations. Their work is not focused on multidisciplinary products.

Another approach envisioned for PDSCT selection is through direct comparison between them. One example of such a comparison is proposed by (Fitsilis, 2008), who compares PMBOK and Agile - XP, Scrum and FDD - through nine criteria groups: project integration management, project scope, project time, cost, quality and human resources management, communications, risk management and procurement management.

Still on the same philosophy of comparing PDSCTs, (Schuh et al., 2015) tried to determine whether a stage-gate or a highly iterative approach such as Agile should be used for module development. A module is, according to the authors citing Baugmart, "a functional and describable unit which should be as independent as possible from other modules". The decision to use stage-gate or an iterative method is based on the sum of five criteria values. These criteria are customer relevance, solution space, degree of freedom, uncertainty and the number of variants.

Another work, by (Cormier and Lewis, 2010), finds that "a new product design (or re-design) problem [poses] a challenging task to determine what methods or paradigms to subscribe to and implement; part of this decision involves whether to design a single product or a set of similar products". To solve this task, they propose "an approach to support this meta-design decision using market segmentation data and appropriate contextual information". Nevertheless, their work is focused mainly on final consumer satisfaction. The emphasis is not placed on MPD, even though this work is able to address MPD, as the use-case demonstrates.

PDSCT selection is currently applied to achieve different goals, but not expressly for selection in an MPD context. The missing point is MPD-oriented criteria. The next sub-section focuses on finding the criteria related to MPD by exploring the literature.

\subsection{MPD issues and features: Emergence of criteria}

The MPD context, by its specificity, induces specific criteria for method selection. As no studies to date have addressed a formalized list of criteria with which to characterize MPD, a step back is needed; looking at MPD features through its issues and expectations and then using that information to establish a list of criteria.

First, the ever-increasing complexity and integration of products seems to be a starting point of MPD issues (Krehmer et al., 2009; Bricogne, 2015; Den Hollander, 2015). Common issues are the lack of communication and silo-thinking, as highlighted by (Bricogne, 2015; Den Hollander, 2015). According to Bricogne, silo-thinking and poor communication combined with overly complex planning and topdown information diffusion within companies pose the major hurdles to functional and physical integration, leading to low system integration. Silo-thinking unfortunately means that only a few people have an overall vision of a project and its issues encountered by different teams.

Disciplines' interfaces are usually set in the early design stages, and must be stable to ensure product integration. Discipline interfaces can also be product interfaces, (Krehmer et al., 2009) adds that various boundary conditions and restrictions must also be considered in the early stages, which can be contrary to how a project progresses, as that can be both unforeseeable and iterative. For system definition, (Zheng, 2015) highlights four different system interfaces that have been validated on a mechatronic use-case. In addition to interfaces, (Den Hollander, 2015) also states that dependencies between disciplines could block the integration of deliverables, and thus increase the problems that can occur during MPD. A possible explanation is given by Bricogne, who states that product integration is mostly considered as a step that emerges at the end of each design of each discipline involved. Therefore, the importance of collaboration, intense communication and human interactions should not be overlooked.

Product integration is strongly dependent on organizational integration, which explains the need to integrate engineering activities, interdependent information and expertise, as a close link between disciplines is desirable. Based on the statement made by Shetty and Kolk, Bricogne underscores theproblems for requirement attribution to the different disciplines involved, as well as the communication issues surrounding design evolutions and a system's digital model. As for digital models, the integration of CAx-aspects is also emphasized by (Krehmer et al., 2009), now that MPD is 
increasingly supported by CAD tools. This criteria is one among others presented by (Krehmer et al., 2009), specifically, that product development should integrate mechatronic aspects, incorporate a situation-specific process planning for the integration of design iterations, integrate "lessons learned", multiple viewpoints through Design for $\mathrm{X}$ aspects, multi-level safeguarding (system decomposition), ensure a dynamic connection between the process model and its product models, support decision making, search for quality enhancing measures and integrate both simultaneous and concurrent engineering. On this last criterion, Bricogne also states that some companies still consider that mechatronic design should be managed using a sequential approach, leading to poorly integrated products. (Krehmer et al., 2009) found a lack of adaptability among processes such as Pahl \& Beitz, Vmodel, a model of System Engineering, and in VDI guidelines 2222, 2223 and 2206. Krehmer et al. therefore propose criteria to be used to design an adaptive process model, the Forflow process, which evolves based on: "risk, kind of development, type of product, persons working on the project and workload".

Encompassing the development context, extended enterprise, sometimes coupled with geographic dispersion, also adds difficulties (Krehmer et al., 2009; Bricogne, 2015). As part of the MPD context, (Krehmer et al., 2009) state that innovation cycles need to be shortened, and that the demand for higher quality is permanently increasing, both transposed into shorter times-to-market and the need to integrate and identify quality-level criteria.

Finally, Bricogne highlights some practices to provide a more integrated product, such as making use of a common modelling language to promote a common referential in the early stages, and global solution and optimization over multiple and separated discipline-centred optimizations.

To synthetize, PCTSL exists but is rarely defined and utilized. PDSCT selection establishes a link and relies on criteria, but few of them explore the multidisciplinary dimension. Moreover, none of them integrate different PDSCT levels. Finally, features related to an MPD context are brought to the fore. These features will be transposed into criteria and enriched in the next section.

\section{Criteria for multidisciplinary product development}

This section presents lists of criteria for PDSCT selection. The tables are partly generated based on criteria presented above in Section 3. These input elements help to fulfil the first two columns. To validate and complete the list of existing criteria found in the literature, twelve semi-directive interviews were led with French and Quebec-based manufacturers and actors of MPD (Lefèvre, 2003). Criteria emerging from these interviews are marked with "(Int)". The second column was generated based on criteria cited in the literature review and from interviews, but also on refinement of the first column. The rest of the "representative criteria" were found by looking at development processes and considering which data could characterize and intercede in an MPD and thus help to select the appropriate PDSCT. Finally, four perspectives were established and are presented in the following sections: context-related criteria, PDSCT features, discipline-specific requirements and multidisciplinary product's features. Each of the following subsections presents one of these perspectives in a table form, mapped with the relevant level addressed by the criteria. This is specified with "A" standing for approach, "P" for process, "M" for method, and "T" for tool. Criteria which support or are supported by the Industrie 4.0 trend are marked with "[I4.0]".

\subsection{Product development context: Company and project}

In order to sort and list PDSCT for MPD and then select the appropriate one that best suits the product to develop, context must be taken into account, as it sets the project overview and specific expectations. This point of view is shared by (Petersson and Lundberg, 2016), who highlight that "one reason for methods not being adopted in industry may be that they are not adapted to the context". Table 1 therefor presents a list of criteria related to a project's context. Different topics are covered and represented by representative criteria column. The contextual scope is represented by the teamwork, human resources and communication aspects, a company's size, its risk management, industrial sector, regulatory constraints, and project data such as a project's duration, costs, contract type and quality management. 
Table 1. Characterization of MPD context through a criteria-based perspective to identify the levels of PDSCT involved

\begin{tabular}{|c|c|c|}
\hline MPD consideration & Representative criteria & $\begin{array}{r}\text { Relevant } \\
\text { level }\end{array}$ \\
\hline \multirow{7}{*}{$\begin{array}{l}\text { MPD success partly relies on team work. } \\
\text { Integration between disciplines is sought } \\
\text { to reach product integration. Thus, this line } \\
\text { addresses criteria about teamwork and } \\
\text { human resources. Geographic dispersion } \\
\text { and extended enterprise context also } \\
\text { impact teamwork. (Fitsilis, 2008; Krehmer } \\
\text { et al., 2009; Ovesen, 2012; Bricogne, } \\
2015 \text { ). }\end{array}$} & $\begin{array}{l}\text { Workload management (Gidel and Zonghero, } \\
\text { 2006) }\end{array}$ & $\mathrm{P}-\mathrm{T}$ \\
\hline & Team size & $\mathrm{P}-\mathrm{M}$ \\
\hline & Team composition (Ovesen, 2012) & $\mathrm{P}-\mathrm{M}$ \\
\hline & Team's integration (Int) [I4.0] & $\mathrm{P}-\mathrm{M}$ \\
\hline & $\begin{array}{c}\text { Disciplines interfaces and dependencies (Den } \\
\text { Hollander, 2015) [I4.0] }\end{array}$ & A - P- M \\
\hline & Geographic dispersion (Bricogne, 2015) [I4.0] & $\mathrm{A}-\mathrm{P}$ \\
\hline & $\begin{array}{l}\text { Extended enterprise (Krehmer et al., 2009; } \\
\text { Bricogne, 2015) }\end{array}$ & A - P \\
\hline \multirow{5}{*}{$\begin{array}{l}\text { MPD team collaboration relies on } \\
\text { communication and information } \\
\text { management (Fitsilis, 2008; Bricogne, } \\
\text { 2015; Den Hollander, 2015). }\end{array}$} & Communication within teams & M \\
\hline & Communication between teams & $\mathrm{P}-\mathrm{M}$ \\
\hline & Information diffusion (Bricogne, 2015) & $\mathrm{A}-\mathrm{P}$ \\
\hline & $\begin{array}{l}\text { Information interdependencies' management } \\
\text { (Bricogne, 2015) }\end{array}$ & $\mathrm{P}-\mathrm{M}$ \\
\hline & Provide a common referential (Bricogne, 2015) & $\mathrm{M}-\mathrm{T}$ \\
\hline \multirow{4}{*}{$\begin{array}{l}\text { MPD is also concerned with project data } \\
\text { such as duration, costs, quality level and } \\
\text { contract type (Gidel and Zonghero, 2006; } \\
\text { Fitsilis, 2008). Duration, costs, contracts, } \\
\text { and quality should be properly managed. }\end{array}$} & $\begin{array}{l}\text { Project duration and its management (Fitsilis, } \\
\text { 2008) }\end{array}$ & $\mathrm{P}-\mathrm{T}$ \\
\hline & $\begin{array}{l}\text { Project costs and its management (Gidel and } \\
\text { Zonghero, 2006; Fitsilis, 2008) }\end{array}$ & $\mathrm{P}-\mathrm{T}$ \\
\hline & Contract type (Gidel and Zonghero, 2006) & A - P \\
\hline & $\begin{array}{l}\text { Project quality management (Krehmer et al., } \\
\text { 2009) }\end{array}$ & $\mathrm{P}-\mathrm{M}$ \\
\hline \multirow{3}{*}{$\begin{array}{l}\text { MPD is risky as companies are evolving in } \\
\text { an uncertain environment with new } \\
\text { technologies. Thus, risk management } \\
\text { should be considered and integrated } \\
\text { (Fitsilis, 2008; Krehmer et al., 2009). }\end{array}$} & Integrated to company & A \\
\hline & Integrated to processes & $\mathrm{P}$ \\
\hline & $\begin{array}{c}\text { Supported by method and tools, integrated to } \\
\text { teams }\end{array}$ & $\mathrm{M}-\mathrm{T}$ \\
\hline $\begin{array}{l}\text { MPD is observable in numerous industrial } \\
\text { sectors. The industrial sector is an } \\
\text { important part of the context as it affects } \\
\text { the value of other criteria such as } \\
\text { regulations or product pricing. }\end{array}$ & Industrial sector [I4.0] & $\mathrm{A}-\mathrm{P}-\mathrm{M}-\mathrm{T}$ \\
\hline $\begin{array}{l}\text { MPD is also influenced by regulations, } \\
\text { constraints and must-use standards. }\end{array}$ & Standard and certification (Int) & $\mathrm{P}-\mathrm{M}$ \\
\hline $\begin{array}{l}\text { Company size could impact the ease of } \\
\text { PDSCT implementation, the ease of } \\
\text { communication and overall organisation. }\end{array}$ & Company size & A - P \\
\hline
\end{tabular}

\subsection{Features of Product Development Supporting Concepts and Techniques}

Each PDSCT has features which characterize how it operates and what it is able and not able to cover. Table 2 presents a set of these features. Time-to-market conditions planning which takes one of two values: strong or light. Time-to-market is also linked to the iterative and incremental nature, and the concurrent or sequential fashion of the process. MPD projects are subject to changes that must be managed. Newly created PDSCT are not always validated in an industrial context and a roadmap is 
sometimes needed to guide companies through their implementation. An existing roadmap is thus a criteria, depending on a company's admissible risk level. Requirements are the starting point of most projects and come from customers and/or product's data logging. In the scope of an MPD, requirements are sometimes distributed between disciplines and interfaces. Their traceability and management is a success factor. In a closely-related concept, design decisions are at the core of product development. A product is a whole set of decisions taken along that product's development, and these must be managed. The criteria about being design-centred is relevant for PDSCT selection. MPD coupled with routine design context (Ullman, 2009) takes full advantage of knowledge-based systems (Le Ber et al., 2006). The last criteria is linked to supporting innovation and creativity management. In an Industrie 4.0 paradigm, software and connectivity integration allow for low-cost innovations.

Table 2. Representation of PDSCT's specific aspects for MPD and their attribution to the appropriate level

\begin{tabular}{|c|c|c|}
\hline PDSCT aspects to support MPD & Representative criteria & Relevant level \\
\hline \multirow{4}{*}{$\begin{array}{l}\text { Time management is an aspect managed by PDSCT to } \\
\text { support MPD. Time-to-market is an MPD concern } \\
\text { (Krehmer et al., 2009) which impacts how products are } \\
\text { developed through planning (strong or light), and their } \\
\text { iterative, incremental and concurrent or sequential nature. }\end{array}$} & $\begin{array}{c}\text { Planning nature (Bricogne, } \\
\text { 2015) }\end{array}$ & A - P \\
\hline & $\begin{array}{c}\text { Concurrent or sequential } \\
\text { nature (Krehmer et al., 2009) }\end{array}$ & $\mathrm{P}$ \\
\hline & Iterative nature (Int) & $A-P$ \\
\hline & Incremental nature (Int) & A - P \\
\hline $\begin{array}{l}\text { Changes can occur during MPD and PDSCT could } \\
\text { manage them. }\end{array}$ & Change management & $\mathrm{P}-\mathrm{M}$ \\
\hline $\begin{array}{l}\text { For an industrial application, an available roadmap for } \\
\text { PDSCT's implementation is an added value. }\end{array}$ & $\begin{array}{l}\text { Existing roadmap (Hoppmann, } \\
\text { 2009) }\end{array}$ & $\mathrm{A}-\mathrm{P}-\mathrm{M}-\mathrm{T}$ \\
\hline \multirow{4}{*}{$\begin{array}{l}\text { PDSCT should support requirement management } \\
\text { attribution and traceability between disciplines in complex } \\
\text { systems, and thus in MPD (Buede, 2009; Bricogne, 2015). } \\
\text { Requirements can be functional or non-functional. } \\
\text { Customer involvement may be required and should be } \\
\text { managed. In an Industrie } 4.0 \text { paradigm, user data can be } \\
\text { registered, processed and reinjected to improve the } \\
\text { product. }\end{array}$} & Non-functional requirements & $\mathrm{M}-\mathrm{T}$ \\
\hline & Functional requirements & $\mathrm{M}-\mathrm{T}$ \\
\hline & Customer's involvement [I4.0] & $\mathrm{A}-\mathrm{P}$ \\
\hline & $\begin{array}{l}\text { User data reutilisation, closed- } \\
\text { loop operation [14.0] }\end{array}$ & $\mathrm{P}-\mathrm{M}$ \\
\hline \multirow{5}{*}{$\begin{array}{l}\text { MPD is a sequence of design choices, thus, design } \\
\text { decision making (DM) should not be overlooked (Pahl et } \\
\text { al., 2007; Krehmer et al., 2009). PDSCT can support } \\
\text { decisions. To support DM, it is important to underline if it } \\
\text { is managed, which decision it could support (concepts and } \\
\text { technical solution selection), and finally, if the selection } \\
\text { relies on indicators (quantitative and/or qualitative). }\end{array}$} & Managed & $\mathrm{P}-\mathrm{M}$ \\
\hline & $\begin{array}{l}\text { DM for technical solution } \\
\text { selection }\end{array}$ & M \\
\hline & DM for concepts selection & $\mathrm{P}-\mathrm{M}$ \\
\hline & Quantitative indicator(s) & $\mathrm{M}$ \\
\hline & Qualitative Indicator(s) & M \\
\hline PDSCT have to support design steps in MPD. & Manage product design & $\mathrm{A}-\mathrm{P}-\mathrm{M}-\mathrm{T}$ \\
\hline \multirow{2}{*}{$\begin{array}{l}\text { In a routine design context (Ullman, 2009), knowledge- } \\
\text { based engineering (KBE) and capitalization are relevant. } \\
\text { PDSCT should integrate knowledge concerns for MPD. }\end{array}$} & $\begin{array}{l}\text { Capitalize on lessons learned } \\
\text { (Krehmer et al., 2009) }\end{array}$ & $A-P$ \\
\hline & Integrate KBE & $\mathrm{A}-\mathrm{P}$ \\
\hline $\begin{array}{l}\text { Developing innovative products is perceived as a success } \\
\text { factor for companies. PDSCT can support this concern in } \\
\text { an MDP context. }\end{array}$ & Creativity management [I4.0] & $\mathrm{M}-\mathrm{T}$ \\
\hline
\end{tabular}

\subsection{Discipline-specific requirements}

MPD could be seen as a whole set of disciplines looking for the synergy and integration between them. To avoid silo thinking, which creates issues such as low product integration or quality, the decomposition and requirements attribution to each discipline should be processed as late as possible. 
Nevertheless, as highlighted earlier, few PDSCT were developed for MPD. Instead, most contribute to solving discipline-specific problems, which must be considered in MPD. Making this point, it appears that hybridization between PDSCT seems to be unavoidable in order to integrate the different disciplines' issues and features.

Table 3 lists some of the criteria related to software, hardware and connectivity development issues that must be taken into account in MPD. Software-related criteria are essentially concerned with quality problems and security aspects. Hardware-related criteria focus on design for X issues, as proposed by (Krehmer et al., 2009), and on tests on both mechanical and electronic design. In some industrial sectors such as aeronautics, due to very strict regulations, components must be tested in real conditions for reliability and robustness validation. Connectivity also has its specific concerns. Table 3 presents three of them: cyber security, compatibility and resilience tests. Cyber security is, as in software security, of particular concern for recent products which could be hacked remotely. As different wireless technologies have emerged and are still emerging, some are unstandardized and so interoperability and compatibility may need to be addressed. Resilience tests are submitted to regulations and standards.

Table 3. Discipline-specific criteria and attribution to the relevant PDSCT level

\begin{tabular}{|c|c|c|c|}
\hline MPD consideration & Discipline & Representative criteria & Relevant level \\
\hline \multirow{12}{*}{$\begin{array}{l}\text { By definition, MPD } \\
\text { integrates multiple } \\
\text { disciplines. Each of } \\
\text { them maintain their } \\
\text { specificities and } \\
\text { issues. MPD should } \\
\text { integrate the different } \\
\text { considerations of the } \\
\text { disciplines involved. }\end{array}$} & \multirow[t]{4}{*}{ Software } & Avoid technical debt (Int) & $M-T$ \\
\hline & & Integrate maintainability & $\mathrm{M}$ \\
\hline & & Integrate security aspects and tests (Int) [I4.0] & $\mathrm{P}-\mathrm{M}$ \\
\hline & & Integrate build and compilation tests & $\mathrm{P}-\mathrm{M}$ \\
\hline & \multirow[t]{5}{*}{ Hardware } & Design for X (Krehmer et al., 2009) & M \\
\hline & & Use and/or support prototyping [I4.0] & M \\
\hline & & Use and/or support numeric simulation & $\mathrm{M}-\mathrm{T}$ \\
\hline & & Tests related to mechanical design & $\mathrm{P}-\mathrm{M}$ \\
\hline & & Tests related to electronic components (Int) & $\mathrm{P}-\mathrm{M}$ \\
\hline & \multirow[t]{3}{*}{ Connectivity } & Support cyber security (Int) [I4.0] & $\mathrm{P}-\mathrm{M}$ \\
\hline & & Compatibility tests (Int) [I4.0] & $\mathrm{P}-\mathrm{M}$ \\
\hline & & Resilience tests (Int) [I4.0] & $\mathrm{P}-\mathrm{M}$ \\
\hline
\end{tabular}

\subsection{Product's overall criteria}

A product is the outcome of the different PDSCT used throughout the MPD process. Most product developments face difficulties that a suitable PDSCT could overcome. Some of these difficulties are specific to the product; its non-functional requirements, its interfaces, the maturity level of the implemented technologies, and the targeted level of product integration are some examples. Thus, a product should be characterized in order to integrate the PMLS as early as possible. Therefore, a product's main features must be considered when choosing the PDSCT to deploy.

Table 4 is a non-exhaustive list of influencing criteria. Technology maturity level is considered. A multidisciplinary product is a collection a technologies brought by the involved disciplines. A technology's maturity level can be assessed thanks to its technology readiness level (TRL). It is multivalued: high (TRL 7-9), intermediate (TRL 5-6) and low (TRL 3-4). Some of these technologies could have a low TRL, which increases product development risks as the technology is still in progress towards maturity. Thus, TRL could be used as a risk indicator. Product integration is sought and must be considered when choosing the approach. (Warniez et al., 2012) define four levels of product integration: separated, joined, included and merged. Product integration is conditioned by team integration, collaboration, communication and by the avoidance of silo-thinking. Product interfaces could be indistinct due to merging components, or well-defined, depending on the desired integration level. MPD is complex, and a global versus a local optimization or solution and multi-physics simulations are required. The last criteria illustrate some of the non-functional requirements. 
Table 4. Criteria-based characterization of multidisciplinary products' features to identify the level that support them

\begin{tabular}{|c|c|c|}
\hline Multidisciplinary products' (MP) features to support & Representative criteria & Relevant level \\
\hline $\begin{array}{l}\text { MP integrates a set of technologies from different disciplines. } \\
\text { Some may not be harnessed by the company. }\end{array}$ & $\begin{array}{l}\text { Technology's maturity level } \\
\text { [I4.0] (Int) }\end{array}$ & $\mathrm{M}$ \\
\hline $\begin{array}{l}\text { A tight integration between components is sometimes sought in an } \\
\text { MP. Defining the targeted level helps to choose the appropriate } \\
\text { PDSCT. Four values have been proposed (Warniez et al., 2012). }\end{array}$ & $\begin{array}{l}\text { Product integration (Warniez } \\
\text { et al., 2012) (Int) [I4.0] }\end{array}$ & $\mathrm{A}-\mathrm{P}-\mathrm{M}$ \\
\hline \multirow{2}{*}{$\begin{array}{l}\text { MPD leads to the involvement of various disciplines, inducing } \\
\text { interfaces on teams as well as on the product itself. These interfaces } \\
\text { could be defined (Zheng, 2015), and/or be flexible. In the case of a } \\
\text { modular design choice, these two criteria are relevant to analyse. }\end{array}$} & $\begin{array}{l}\text { Allow and manage flexible } \\
\text { interfaces }\end{array}$ & $\mathrm{P}-\mathrm{M}$ \\
\hline & Support interfaces definition & $\bar{M}$ \\
\hline \multirow{3}{*}{$\begin{array}{l}\text { In an MPD context, the solution and the optimum to find are } \\
\text { global and simulation should be multi-physics-based (Bricogne, } \\
\text { 2015). This is the MP view. }\end{array}$} & Global over local optimum & $\mathrm{P}-\mathrm{M}$ \\
\hline & Multi-physics simulation & $\bar{M}$ \\
\hline & Global over local solution & $\mathrm{P}-\mathrm{M}$ \\
\hline \multirow{7}{*}{$\begin{array}{l}\text { MPD have to consider, manage and respond to the non-functional } \\
\text { requirements expected of products. Products are expected to be } \\
\text { reliable, robust, maintainable and secure. In an Industrie } 4.0 \\
\text { paradigm, products can be autonomous, adaptable, stable and } \\
\text { precise. Developing and managing eco-responsible products and } \\
\text { analyzing their environmental impact is sometimes a concern in a } \\
\text { MPD context. }\end{array}$} & Reliability & $\mathrm{P}-\mathrm{M}$ \\
\hline & Robustness & $\mathrm{P}-\mathrm{M}$ \\
\hline & Maintainability & $\mathrm{M}$ \\
\hline & $\begin{array}{l}\text { Autonomy and adaptability } \\
\text { (Krehmer et al., 2009) [I4.0] }\end{array}$ & $\mathrm{M}$ \\
\hline & (Operational) Security & $\mathrm{P}-\mathrm{M}$ \\
\hline & $\begin{array}{c}\text { System's stability and } \\
\text { precision [14.0] }\end{array}$ & $\bar{M}$ \\
\hline & $\begin{array}{c}\text { Environmental impact (Int) } \\
\text { (Krehmer et al., 2009) }\end{array}$ & A - P-M -T \\
\hline
\end{tabular}

\section{Conclusion and outlook}

To summarize, current multidisciplinary products are of growing importance and part of the digital and connectivity era. Emerging technologies such as M2M, autonomous machines, simulation, the internet of things (IoT), cyber security, cloud computing, augmented reality, big data and analysis, CPS and artificial intelligence are positioned as building blocks of Industrie 4.0 (Danjou et al., 2017). Industrie 4.0 is the industry's response to the trend of connectivity integration.

This paper investigates the opportunity to establish a list of criteria in order to sort PDSCT based on their abilities to support MPD. A list of criteria has been proposed and organized into four categories which address different MPD perspectives. The list does not claim to be exhaustive. The first perspective is context-relative criteria. Context establishes a project's perimeter and influences its realization on various aspects; its importance should not be overlooked. The second perspective is focused on PDSCT features and identifying which have to be supported in an MPD context. The third perspective addresses discipline-specific characteristics and expectations. Each discipline has its technical problems or inner issues that must be solved along with a product's development. This perspective aims to highlight that MPD, even if taken as a global set, is a result of a composition of different disciplines that must be managed according to their features and respective backgrounds. Finally, the fourth perspective is related to a product's overall specificities and how they can influence PDSCT selection.

This article is positioned as a cornerstone that outlines the need for MPD evaluation. In terms of a research project's outlook, a set of selected PDSCTs is needed to support MPD. Hybridization between some of them must be considered and are already being used in industry. Indeed, looking at the criteria and the levels addressed, it remains to be seen if an approach, a process, a method and a tool are able to respond well to all of them. Hybridization thus appears to be a possible answer to MPD. Hybridization could also act in each discipline or work package that are then able to use the suitable PDSCT to fulfil their purpose.

\section{Acknowledgment}

This work has been supported by France's "Fonds Unique Interministériel - FUI19 programme" and assisted by System@TIC and i-Trans competitiveness clusters (the MIMe project). The authors are grateful to all of the consortium partners for their valuable contribution during the development of ideas and concepts. 


\section{References}

Abramovici, M. and Bellalouna, F. (2007), "Integration and Complexity Management within the Mechatronics Product Development”, In: Takata, S. and Umeda, Y. (Eds.), Advances in Life Cycle Engineering for Sustainable Manufacturing Businesses, Springer, London, pp. 113-118. https://doi.org/10.1007/978-1-84628-935-4_20

Anderl, R.A. (2014), "Industrie 4 . 0 - Advanced Engineering of Smart Products and Smart Production", $19^{\text {th }}$ International Seminar on High Technology, Piracicaba, Brasil. https://doi.org/10.13140/2.1.1039.4406

Baheti, R. and Gill, H. (2011), "Cyber-physical Systems”, In: Samad, T. and Annaswamy, A.M. (Eds.), The Impact of Control Technology, IEEE Control Systems Society, Munich, pp. 161-166.

Beck, K., Beedle, M., Van Bennekum, A., Cockburn, A., Cunningham, W. et al. (2001), Agile Manifesto. [online] Software Development. Available at: www.agilemanifesto.org

Booch, G., Jacobson, I. and Rumbaugh, J. (2007), Object-Oriented Analysis and Design with Applications, 3rd ed., Addison-Wesley, Santa Clara, CA.

Bricogne, M. (2015), Méthode Agile pour la conception collaborative multidisciplinaire de systèmes intégrés : application à la Mécatronique, $\mathrm{PhD}$ thesis, Université de Technologie de Compiègne.

Bricogne, M., Le Duigou, J. and Eynard, B. (2016), "Design Processes of Mechatronic Systems", In: Hehenberger, P. and Bradley, D. (Eds.), Mechatronic Futures, Springer, Cham, pp. 75-89. https://doi.org/10.1007/978-3-319-32156-1_6

Buede, D.M. (2009), The Engineering Design of Systems: Models and Methods, 2nd ed., John Wiley \& Sons, Inc., Hoboken, New Jersey. https://doi.org/10.1002/9780470413791

Cooper, R.G. and Sommer, A.F. (2016), "The Agile-Stage-Gate Hybrid Model: A Promising New Approach and a New Research Opportunity", Journal of Product Innovation Management, Vol. 33 No. 5, pp. 513-526. https://doi.org/10.1111/jpim.12314

Cormier, P. and Lewis, K. (2010), "Design Method Selection to Satisfy Consumer Variation: A Meta-Design Approach", Proceedings of the 22nd International Conference on Design Theory and Methodology, Montreal, Canada, August 15-18, 2010, ASME, pp. 93-106. https://doi.org/10.1115/DETC2010-28901

Crnkovic, I., Asklund, U. and Dahlqvist, A.P. (2003), Implementing and Integrating Product Data Management and Software Configuration Management, Artech House, Boston \& London.

Cronin, M.J. (2010), Smart Products, Smarter Services, Smart Products, Smarter Services: Strategies for Embedded Control, Cambridge University Press, Cambridge. https://doi.org/10.1017/CBO9780511761928

Danjou, C., Rivest, L. and Pellerin, R. (2017), Industrie 4.0 : Des pistes pour aborder l'ère du numérique et de la connectivité, Cefrio.

Den Hollander, M. (2015), "Organizational patterns for multidisciplinary development of a mechatronic system", Proceedings of the 20 th European Conference on Pattern Languages of Programs ( EuroPLoP '15), Kaufbeuren, Germany, July 8-12, 2015, ACM Press, New York. https://doi.org/10.1145/2855321.2855372

Ebert, C. (2013), "Improving engineering efficiency with PLM/ALM", Software and Systems Modeling, Vol. 12 No. 3, pp. 443-449. https://doi.org/10.1007/s10270-013-0347-3

Estefan, J.A. (2008), Survey of Model-Based Systems Engineering ( MBSE ) Methodologies, INCOSE MBSE Initiative, Pasadena, California, USA.

Fitsilis, P. (2008), "Comparing PMBOK and Agile Project Management software development processes", In: Sobh, T. (Ed.), Advances in Computer and Information Sciences and Engineering, Springer, Dordrecht, pp. 378-383. https://doi.org/10.1007/978-1-4020-8741-7_68

Fricker, S.A. (2012), "Software Product Management", In: Maedche, A., Botzenhardt, A. and Neer, L. (Eds.), Software for People, Management for Professionals, Springer, Berlin, Heidelberg, pp. 53-81. https://doi.org/10.1007/978-3-642-31371-4_4

Gad-el-Hak, M. (2002), The MEMS Handbook, CRC Press.

Gidel, T. and Zonghero, W. (2006), Management de Projet: Approfondissements, Hermes Science, Lavoisier.

Girard, P. and Doumeingts, G. (2004), "Modelling the engineering design system to improve performance", Computers \& Industrial Engineering, Vol. 46 No. 1, pp. 43-67. https://doi.org/10.1016/j.cie.2003.09.008

Giusto, D., Iera, A., Morabito, G. and Atzori, L. (2010), The Internet of Things: 20th Tyrrhenian Workshop on Digital Communications, Springer, New York. https://doi.org/10.1007/978-1-4419-1674-7

Guérineau, B., Rivest, L., Bricogne, M. and Durupt, A. (2016), "Agile and Project-Planned Methods in Multidisciplinary Product Design", The 13th IFIP International Conference on Product Lifecycle Management (PLM16), Columbia, SC, USA, Springer, Cham, pp. 108-118. https://doi.org/10.1007/978-3-319-54660-5_11

Hehenberger, P., Poltschak, F., Zeman, K. and Amrhein, W. (2010), "Hierarchical design models in the mechatronic product development process of synchronous machines", Mechatronics, Vol. 20 No. 8, pp. 864875. https://doi.org/10.1016/j.mechatronics.2010.04.003

Hermann, M., Pentek, T. and Otto, B. (2016), "Design Principles for Industrie 4.0 Scenarios", Proceedings of HICSS 2016 / the 49th Hawaii International Conference on System Sciences, Koloa, USA, IEEE, pp. 39283937. https://doi.org/10.1109/HICSS.2016.488 
Hoppmann, J. (2009), The Lean Innovation Roadmap - A Systematic Approach to Introducing Lean in Product Development Processes and Establishing a Learning Organization, Master thesis, University of Braunschweig.

Hu, F., Lu, Y., Vasilakos, A.V., Hao, Q., Ma, R. et al. (2016), "Robust Cyber-Physical Systems: Concept, models, and implementation", Future Generation Computer Systems, Vol. 56, pp. 449-475. https://doi.org/10.1016/j.future.2015.06.006

Isermann, R. (2002), “Mechatronic Design Approach”, In: Bishop, R.H. (Ed.), The Mechatronics Handbook, CRC

Kääriäinen, J. and Välimäki, A. (2009), "Applying application lifecycle management for the development of complex systems: Experiences from the automation industry", Proceedings of the $16^{\text {th }}$ Eurpoean Conference (EuroSPI 2009), Madrid, Spain, Springer, pp. 149-160. https://doi.org/10.1007/978-3-642-04133-4_13

Kagermann, H., Wahlster, W. and Helbig, J. (2013), Recommendations for implementing the strategic initiative INDUSTRIE 4.0, Final Report of the Industrie 4.0 WG, Platform Industrie 4.0, Frankfurt.

Kleiner, S. and Kramer, C. (2013), "Model Based Design with Systems Engineering Based on RFLP Using V6", Proceedings of the $23^{\text {rd }}$ CIRP Design Conference, Bochum, Germany, March 11-13, 2013, Springer, Berlin, Heidelberg, pp. 93-102. https://doi.org/10.1007/978-3-642-30817-8_10

Krehmer, H., Eckstein, R., Laufer, W., Roelofsen, J., Stöber, C. et al. (2009), "Coping with Multidisciplinary Product Development - A Process Model Approach", Proceedings of the $17^{\text {th }}$ International Conference on Engineering Design (ICED '09), Palo Alto, USA, The Design Society, pp. 241-252.

Le Ber, F., Lieber, J. and Napoli, A. (2006), "Les systèmes à base de connaissances", In: Akoka, J. and ComynWattiau, I. (Eds.), Encyclopédie de L'informatique et Des Systèmes D'information, Vuibert, pp. 1197-1208.

Lefèvre, N. (2003), L'entretien Comme Méthode de Recherche. [online] Available at: http://madagascarinterculturel.e-monsite.com/medias/files/methodo-plan-et-biblio.pdf

Nomaguchi, Y., Askhøj, A., Madsen, K.F., Akai, R. and Fujita, K. (2012), "Design Method Selection Matrix for Facilitating Product Platform and Family Design", ASME 2012 International Design Engineering Technical Conferences and Computers and Information in Engineering Conference, Vol. 5, Chicago, Illinois, August 1215, 2012, ASME, pp. 643-657. https://doi.org/10.1115/DETC2012-70861

Ovesen, N. (2012), The Challenges of Becoming Agile: Implementing and Conducting Scrum in Integrated Product Development, PhD thesis, Aalborg University.

Pahl, G., Beitz, W., Feldhusen, J. and Grote, K.-H. (2007), Engineering Design: A Systematic Approach, Springer London. https://doi.org/10.1007/978-1-84628-319-2

Petersson, A.M. and Lundberg, J. (2016), “Applying Action Design Research (ADR) to Develop Concept Generation and Selection Methods", Procedia CIRP, Vol. 50, pp. 222-227. https://doi.org/10.1016/j.procir.2016.05.024

Rajkumar, R. (2012), "A cyber-physical future”, Proceedings of the IEEE, Vol. 100, pp. 1309-1312. https://doi.org/10.1109/JPROC.2012.2189915

Schuh, G., Rudolf, S. and Diels, F. (2015), "Methodology for the evaluation and selection of the suitability of highly iterative product development methods for individual segments of an overall development project", Proceedings of the 2015 IEEE International Conference on Industrial Engineering and Engineering Management (IEEM), Singapore, IEEE, pp. 661-665. https://doi.org/10.1109/IEEM.2015.7385730

Schwaber, K. (1997), “SCRUM Development Process”, In: Sutherland, J., Casanave, C., Miller, J., Patel, P. and Hollowell, G. (Eds.), Business Object Design and Implementation, Springer, London, pp. 117-134. https://doi.org/10.1007/978-1-4471-0947-1_11

Stolberg, S. (2009), "Enabling agile testing through continuous integration", Proceedings of the 2009 Agile Conference, Chicago, USA, August 24-28, 2009, IEEE, pp. 369-374. https://doi.org/10.1109/AGILE.2009.16

Suh, N.P. (1998), “Axiomatic Design Theory for Systems”, Research in Engineering Design, Vol. 10 No. 4 , pp. 189-209. https://doi.org/10.1007/s001639870001

Turki, S., Lismma, T.S. and Sghaier, A. (2005), "A SysML profile for mechatronics integrating bond graphs", Proceedings of the 9th WSEAS International Conference Circuits, Communications, Computers (CSCC), Athens, Greece, July 11-16, 2005.

Ullman, D.G. (2009), The Mechanical Design Process, $4^{\text {th }}$ ed., McGraw-Hill Education.

VDI (2004), VDI-Guideline 2206 : Design Methodology for Mechatronic System, Beuth Verlag.

Warniez, A., Penas, O. and Soriano, T. (2012), "About metrics for integrated mechatronic system design", Proceedings of Mecatronics REM 2012, Paris, France, November 21-23, 2012, IEEE, pp. $450-457$. https://doi.org/10.1109/MECATRONICS.2012.6451047

Zheng, C. (2015), Design and Integration of Multi-Disciplinary Interfaces : Method and Modelling Language for Mechatronic Systems Engineering, PhD thesis, Université de Technologie de Compiègne.

Benjamin-Julia Guérineau, PhD Student

University of Technology of Compiègne, Mechanical engineering

4 Route de Raville, 28410 Serville, France

Email: benjamin.guerineau@utc.fr 